\title{
A EstabilizaÇÃo dA TUTELA ANTECIPADA COMO INSTRUMENTO DE EFETIVIDADE DA JURISDIÇÃO EM FACE DO DIREITO FUNDAMENTAL AO CONTRADITÓRIO
}

\author{
NATALIA PINHEIRO ${ }^{\dagger}$ \\ JULIANA CRISTINE Diniz CAMPOS ${ }^{\dagger \dagger}$
}

RESUMO: O presente artigo tem como objeto de estudo o instituto processual de estabilização da tutela antecipada de urgência e como perspectiva de análise a teoria dos direitos fundamentais. Pretende-se investigar a fundamentalidade material do instituto tomando como premissa teórica a dupla natureza do princípio do acesso à justiça enquanto direito e garantia fundamental. Nessa linha de pesquisa, defende-se a tutela antecipada de urgência e sua estabilização como regra instrumental do direito fundamental de acesso à justiça e como conteúdo assecuratório derivado da garantia fundamental de acesso à justiça. Defende-se, contudo, que a fundamentalidade material do instituto somente poderá ser sustentada se a estabilidade de uma tutela proferida no âmbito da cognição sumária não ofender, em sua gênese, o direito fundamental ao contraditório.

PAlavras-Chave: Estabilidade da Tutela Antecipada de Urgência; Fundamentalidade Material; Direito Fundamental ao Contraditório.

\footnotetext{
${ }^{\dagger}$ Mestranda em Direito (Ordem Jurídica Constitucional) e Bacharel em Direito pela Universidade Federal do Ceará.

† Professora Adjunta do Departamento de Direito Processual e do Programa de PósGraduação em Direito, com área de concentração em Direito Constitucional, da Universidade Federal do Ceará. Doutora em Direito do Estado pela Universidade de São Paulo. Bacharel em Direito e Mestre em Direito (Direito e Desenvolvimento) pela Universidade Federal do Ceará.
} 


\begin{abstract}
This article has as object of study the stabilization of the summary judgment of urgency Institute, and as an analytical perspective the theory of fundamental rights. We intend to investigate the material fundamentality of this Institute having as theoretical premise the dual nature of the principle of justice access as a right and a fundamental guarantee. In this research line, we understand the summary judgment of urgency Institute and its stabilization as a tool of the fundamental right of access to justice and as a content derived from the fundamental guarantee of access to justice that assures it. The material fundamentality of the Institute, however, can only be sustained if the stability of a protection given under the summary cognition, doesn't offend, in its genesis, the audi alteram partem principle.
\end{abstract}

KEYWORDS: Stabilization of the Summary Judgment of Urgency Institute; Material Fundamentality; Audi Alteram Partem Principle. 


\section{SUMÁRIO:}

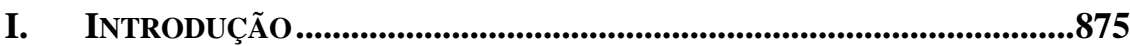

II. As CONCEPÇões TeÓRICAS DA TUTELA JURISDICIONAL LATO SENSU E A COGNIÇÃo SUMÁRIA..................................................876

III. O INSTITUTO Da ANTECIPAÇ̃̃o da TUTELA JURISDICIONAL DE URGÊNCIA E SUA FUNDAMENTALIDAdE MATERIAL...................879

IV. A EstabilizaÇão da Tutela JURISDicional ANTECIPADa EM RAZÃo DA URGÊNCIA E SUA FUNDAMENTALIDADE MATERIAL ....881

V. A Estabilização da TUtela ANTECiPada e o PrincíPIO do CONTRAditóRIO No ÂMBITO da COGNIÇão SUMÁRIA..................885

1. O Modelo Constitucional do Processo Civil Brasileiro.......885

2. O Contraditório no Modelo Constitucional do Processo Civil Brasileiro ......................................................8888

2.1. O Contraditório Prévio...................................................889

2.2. O Contraditório Postecipado ..........................................890

3. Contraditório e Procedimento Sumário na Estabilização da Tutela Antecipada de Urgência ..........891

VI. CONSIDERAÇÕES FINAIS.........................................................................883

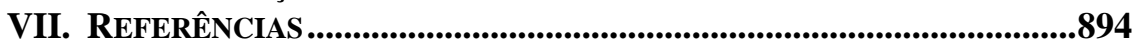




\section{TABLE OF CONTENTS:}

I. INTRODUCTION ...........................................................................................875

II. The Theoretical ConCEPTIONS OF THE JUdicial Protection LATO SENSU AND ITS SUMMARY COGNITION .................................876

III. The Institute of the Judicial Protection Antecipation OF URGENCY AND ITS MATERIAL FUNDAMENTALITY .......................879

IV. The Stabilization of the Judicial Protection ANTECIPATED IN REASON OF URGENCY AND ITS MATERIAL FUNDAMENTALITY.

V. THE STABILIZATION OF THE ANTECIPATED JUDICIAL Protection AND THE AUd alteram PARTEM PRINCIPLE WITHIN THE SUMMARY COGNITION

1. The Constitutional Model of the Brazilian Civil Procedure .885

2. The audi alteram partem Principle in the

Constitutional Model of the Brazilian Civil Procedure .....888

2.1. The Prior audi alteram partem...................................889

2.2. The Posterior audi alteram partem ...............................890

3. Audi alteram partem Principle and the Summary Procedure in the Antecipated Judicial Protection of Urgency Stabilization.

VI. FINAL CONSIDERATIONS ..................................................................889

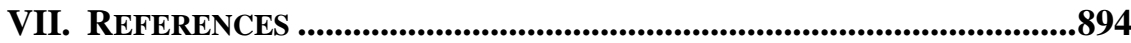




\section{INTRODUÇÃO}

O presente estudo busca contribuir para a construção de uma Jurisdição atenta à efetividade do provimento jurisdicional, partindo-se da premissa de que a aproximação ao valor de Justiça perpassa pela concretude de direitos, em especial, de direitos fundamentais. A partir de tal perspectiva, entende-se que a efetividade da prestação jurisdicional não é somente um direito fundamental per si, como também um instrumento, ou garantia, de alcance dos demais direitos fundamentais.

A morosidade da Jurisdição, contudo, é forte embaraço para a prestação jurisdicional efetiva, acarretando, por diversas vezes, real negação do acesso à justiça e descrédito da atividade jurisdicional. É nesse contexto que a técnica processual, em especial no âmbito cível, desenvolve o conceito de tutela diferenciada. Este instituto tem o condão de promover a efetividade do processo enquanto instrumento de pacificação de conflitos e de aplicação da vontade concreta do direito.

Dentre as espécies de tutelas diferenciadas, tem-se a antecipação da tutela. $\mathrm{O}$ estudo empreende um corte epistemológico que, em razão da perspectiva adotada, delimita o objeto de estudo à antecipação de tutela fundamentada na urgência do caso concreto. Urgência essa, pela própria natureza, intrínseca à concretização de direitos fundamentais de diferentes tipos.

A antecipação, por si, confere baixo grau de segurança jurídica ao seu beneficiário. Razão pela qual se defende o instituto da estabilização da tutela antecipada como instrumento capaz de assegurar maior grau de segurança ao direito tutelado. A tutela estabilizada, contudo, é proferida em estado sumário de cognição, razão pela qual se questiona a consonância do instituto com os princípios constitucionais do processo, em especial, com o princípio do contraditório.

$\mathrm{O}$ instituto da estabilização, apesar de já ensaiado em projetos de reforma do Código de Processo Civil de 1973, apenas foi positivado no ordenamento jurídico brasileiro pelo Novo Código processual. Consiste no instrumento processual o qual torna estável decisão, proferida em procedimento sumário, que antecipa os efeitos da tutela jurisdicional pretendida na hipótese de urgência contemporânea ao ajuizamento da ação.

A produção acadêmica sobre a estabilização no Brasil ainda se encontra em grau inicial de desenvolvimento, não havendo previsão expressa do instituto no ordenamento jurídico do país até o advento do Novo Código. Para além do estágio inicial de debate sobre o tema, a redação do Novo Código é passível de dúvidas, tendo optado por uma técnica processual insuficiente e, em certa medida, contraditória. 
Torna-se necessário, para propor a instrumentalidade da estabilização enquanto ferramenta de efetividade da função jurisdicional do Estado, uma análise sobre sua natureza jurídica. Partindo-se da premissa de que a prestação jurisdicional efetiva goza do caráter duplo de direito e garantia fundamental.

Nesse sentido, problematiza-se como e em que medida a estabilização da tutela antecipada de urgência pode ser instrumento para efetivação da tutela jurisdicional do Estado.

Analisando o problema central delimitado sob a perspectiva dos direitos fundamentais, indaga-se em que medida a estabilização da tutela antecipada de urgência pode ser considerada conteúdo assecuratório da garantia fundamental de prestação jurisdicional efetiva, bem como até que ponto a estabilização da tutela antecipada de urgência pode ser considerada regra instrumental do direito fundamental de prestação jurisdicional efetiva.

O estudo proposto perpassa, ainda, indaga se a estabilização conforme positivada no ordenamento jurídico brasileiro guarda consonância com os princípios constitucionais do processo, em especial o princípio do contraditório.

\section{As CONCEPÇÕES TEÓRICAS DA TUTELA JURISDICIONAL LATO SENSU E A COGNIÇÃo SUMÁRIA}

Para adentrar ao tema da estabilização da tutela antecipada de urgência, ou mesmo da tutela diferenciada, faz-se necessária uma revisão teórica acerca do próprio conceito de tutela jurisdicional. Pontes de Miranda ${ }^{1}$, em interpretação das ideias de Adolf Wach, afirmava que o direito material e o direito processual não se confundiam, de tal modo que não existiria direito à sentença favorável, mas direito à pretensão de sentença.

Esta concepção de que o juízo detém a obrigação de conhecer da demanda como forma derivada da obrigação estatal de administração da justiça, diversificando o direito processual do direito material, também

${ }^{1}$ Cf. PONTES DE MIRANDA, Francisco Cavalcanti. Tratado das ações: Ação, Classificação e Eficácia, Tomo I. 2ª ed. Rio de Janeiro, RJ: Editora Revista dos Tribunais, 1972. 
foi defendida por James Goldschmidt. ${ }^{2}$

Eduardo Couture $^{3}$, ao explorar o direito à tutela jurisdicional, classifica o direito de ação como espécie do direito de petição, aproximando-se daquilo que hoje é entendido como direito constitucional de representação, podendo este abranger a provocação de autoridades jurisdicionais ou não.

Cândido Rangel Dinamarco ${ }^{4}$ associa a tutela jurisdicional ao direito processual, sendo, este último, o setor do ordenamento jurídico que constitui instrumento técnico e ético formado por normas e princípios regentes das atividades destinadas à pacificação social.

A partir da concepção moderna do processo como instrumento para concretização do direito material, percebe-se com maior evidência a função jurisdicional de pacificar os conflitos sociais por meio da aplicação da vontade concreta do Direito. Nesse contexto, ganham força as concepções de tutelas diferenciadas enquanto importantes ferramentas para evitar o esvaziamento do propósito do processo ante as urgências do caso concreto.

Ricardo Leonel de Barros 5 explica que a tutela diferenciada está dissociada da ideia de tutela ordinária, ou tutela comum. Ela deve ser compreendida como a proteção jurídica decorrente de procedimentos especiais pautados na celeridade cuja efetividade da prestação jurisdicional advém de uma cognição sumária.

À cognição sumária, por seu tempo, emprega-se o conceito esposado por Giuseppe Chiovenda ${ }^{6}$, que afirma ser o instituto sinônimo de cognição incompleta, seja no plano horizontal, enquanto cognição parcial; seja no plano vertical, enquanto cognição superficial; constituindo-se também pelo caráter de não-definitividade.

${ }^{2}$ Cf. GOLDSCHMIDT, James. Derecho Procesal Civil. Trad. Leonardo Pietro Castro.

Barcelona: Editorial Labor, S.A., 1936.

${ }^{3}$ Cf. COUTURE, Eduardo J. Introdução ao Estudo do Processo Civil: discursos, ensaios e conferências. Trad. Hiltomar Martins de Oliveira. Belo Horizonte, MG: Editora Líder, 2003.

${ }^{4}$ Cf. DINAMARCO, Cândido Rangel. A instrumentalidade do processo. 15ª ed. São

Paulo, SP: Malheiros, 2013.

${ }^{5}$ Cf. LEONEL, Ricardo de Barros. Tutela jurisdicional diferenciada. São Paulo, SP:

Revista dos Tribunais, 2010.

${ }^{6}$ Cf. CHIOVENDA, Giuseppe. Instituições de Direito Processual Civil. Trad. José Guimarães Menegale. São Paulo, SP: Saraiva, 1965.

2 JOURNAL OF INSTITUTIONAL STUDIES 2 (2016) 
Para Andrea Proto Pisani ${ }^{7}$, a tutela sumária ${ }^{8}$ remete a uma compreensão de cognição inferior em relação à cognição plena. Mencionada inferioridade relaciona-se, contudo, com a garantia processual do instituto e não necessariamente com a qualidade lógica da cognição.

Alex Costa Pereira ${ }^{9}$, em um exercício de ponderação entre cognição e estabilização, chama atenção para os graus de estabilidade de que são dotadas as tutelas antecipatórias. Para Pereira, as modalidades de tutela sumária dispostas no ordenamento jurídico brasileiro têm por objetivo atender à necessidade de harmonia entre valores como a segurança jurídica e a efetividade da tutela jurisdicional.

Segundo o autor (2012), o processo cujo fundamento seja a cognição plena e exauriente é voltado à busca da resposta jurídica ideal para o caso concreto. No entanto, esta forma de procedimento, por diversas vezes, deixa de atender a escopos maiores da jurisdição.

Embora a verdade, no âmbito filosófico, encontre-se no centro do processo cognoscente, enquanto resultado ideal da interação entre sujeito, atividade e objeto cognoscível; no âmbito do direito processual, ela não constitui o escopo principal. Para o processualista moderno, a verdade constitui importante aspecto no pronunciamento jurisdicional que aplicará a vontade concreta do direito. Contudo, ela não constituirá um fim em si mesmo. ${ }^{10}$ Caso contrário fosse, a técnica processual restaria fadada ao não esgotamento do procedimento e a não efetividade da prestação jurisdicional.

7 PROTO PISANI, Andrea. L'istruzioni nei procedimenti sommari. Il Foro Italiano, Vol. 125, 2, 2002, p. 17-24.

${ }^{8}$ Entende-se por "tutela sumária" a tutela diferenciada constante no ordenamento jurídico-processual italiano, conforme será explicado a seguir.

${ }^{9}$ Cf. PEREIRA, Alex Costa. Tutela sumária: a estabilização da tutela antecipada e sua adequação ao modelo constitucional do processo civil brasileiro. Tese (Doutorado em Direito Processual) - Faculdade de Direito, Universidade de São Paulo, São Paulo, 2012. Disponível em: $<$ http://www.teses.usp.br/teses/disponiveis/2/2137/tde-26032013103821/>. Acesso em: 26 de abril de 2015.

${ }^{10}$ DINAMARCO, Cândido Rangel. A instrumentalidade do processo. 15ª ed. São Paulo, SP: Malheiros, 2013, p. 272. 


\section{O INSTITUTO DA ANTECIPAÇÃO DA TUTELA JURISDICIONAL DE URGÊNCIA E SUA FUNDAMENTALIDADE MATERIAL}

A prestação jurisdicional efetiva, pois, é a roupagem que o direito processual contemporâneo emprega ao direito de ação. José Albuquerque Rocha ${ }^{11}$, ao tratar da prestação jurisdicional, emprega-lhe o caráter duplo de direito e garantia fundamental. Para o autor, a prestação jurisdicional efetiva não é apenas um direito fundamental, mas o mais fundamental dos direitos, posto que seja também garantia para a realização concreta dos demais direitos fundamentais.

$\mathrm{O}$ autor elenca, ainda, os efeitos jurídicos decorrentes da fundamentalidade da prestação jurisdicional efetiva, dentre os quais se destaca o caráter de guia obrigatório para a interpretação de todas as regras relativas à tutela jurisdicional. ${ }^{12}$

Considerando a natureza axiológica do direito fundamental à prestação efetiva da tutela jurisdicional, e tomando como premissa a Teoria dos Direitos Fundamentais, tem-se um mandado de otimização cuja satisfação depende de possibilidades fáticas e jurídicas. ${ }^{13}$

Diante de possibilidades fáticas, pode-se afirmar que o direito em análise tem aplicação direta e imediata. Já no que tange às possibilidades jurídicas, cumpre destacar o raciocínio de Willis Santiago Guerra Filho ${ }^{14}$ de que os direitos fundamentais são consagrados como normas jurídicas de natureza principiológica. De que os princípios, por sua vez, são a norma jurídica que positiva um valor e que pressupõe normas jurídicas de outros tipos para ser aplicada.

Alvaro de Oliveira ${ }^{15}$, a seu turno, afirma que os direitos fundamentais,

${ }^{11}$ ROCHA, José de Albuquerque. Teoria Geral do Processo. 9a ed. São Paulo, SP: Editora Atlas, 2007, p. 150-151.

${ }^{12}$ ROCHA, José de Albuquerque. Teoria Geral do Processo. 9a ed. São Paulo, SP: Editora Atlas, 2007, p. 150-151.

${ }^{13}$ Cf. ALEXY, Robert. Teoria dos Direitos Fundamentais. Trad. Virgílio Afonso da Silva. São Paulo, SP: Malheiros, 2008, p. 90.

${ }^{14}$ GUERRA FILHO, Willis Santiago. Processo Constitucional e Direitos

Fundamentais. $6^{\underline{a}}$ ed. São Paulo, SP: SRS Editora, 2009, p. 257-258.

${ }^{15}$ OLIVEIRA, Carlos Alberto Alvaro de. O processo civil na perspectiva dos direitos fundamentais. Cadernos do Programa de Pós-Graduação em Direito - UFRGS, Vol. 2, 4, 2004. Disponível em:

<http://www.seer.ufrgs.br/index.php/ppgdir/article/view/49187/30822>. Acesso em: 09 de setembro de 2015, p. 126-128. 
do ponto de vista processual, para que possam desempenhar sua função na realidade social, precisam de normatização intrinsecamente densificadora e de formas de organização e regulamentação procedimentais apropriadas.

Não obstante, se retomarmos os conceitos de tutela jurisdicional que diferenciam o direito processual do direito material, entendendo aquele como instrumento para obtenção do último e como modo de consagração da jurisdição enquanto atividade estatal voltada à pacificação social com justiça, tem-se que as tutelas diferenciadas cumprem importante função de garantir a efetividade do processo.

Humberto Theodoro Jr. ${ }^{16}$ elenca a antecipação de tutela como espécie do gênero tutela diferenciada. Para o autor, a antecipação da tutela é um direito subjetivo processual que, dentro dos pressupostos rigidamente traçados na legislação, concede à parte o poder de exigir da Justiça a parcela da tutela jurisdicional a que o Estado se obrigou. O autor destaca, ainda, que o instituto é justificado pelo princípio da necessidade e a partir da constatação de que a espera pela prestação jurisdicional implicaria em denegação da justiça. ${ }^{17}$

A doutrina processualista tende a diversificar, dentre as tutelas diferenciadas, as tutelas cautelares de urgência, cuja natureza é tida como assecuratória do direito ao processo; e as antecipatórias de urgência, cuja natureza é tida como assecuratória do direito final pretendido. Para Marcelo Guerra ${ }^{18}$, no entanto, a antecipação dos efeitos da decisão jurisdicional final detém função idêntica às demais medidas cautelares, qual seja, a garantia do resultado útil (efetividade) da prestação jurisdicional.

Sob tais perspectivas, possível afirmar que o instituto da antecipação de tutela, em especial a tutela fundamentada na urgência do pedido, como elemento componente e instrumental do direito fundamental à prestação jurisdicional efetiva.

Tal hipótese pode ser analisada sob duas óticas, análise esta que decorre logicamente da dupla caracterização da prestação jurisdicional

${ }^{16}$ THEODORO JR., Humberto. Curso de Direito Processual Civil: processo de execução e cumprimento da sentença, processo cautelar e tutela de urgência Volume II. 44 ${ }^{\mathrm{a}}$ ed. Rio de Janeiro, RJ: Forense, 2009, p. 664-665.

17 THEODORO JR., Humberto. Curso de Direito Processual Civil: processo de execução e cumprimento da sentença, processo cautelar e tutela de urgência Volume II. 44 ${ }^{\mathrm{a}}$ ed. Rio de Janeiro, RJ: Forense, 2009, p. 664-665.

${ }^{18}$ GUERRA, Marcelo Lima. Estudos sobre o processo cautelar. São Paulo, SP:

Malheiros, 1994, p. 98. 
efetiva como garantia e como direito fundamental. Sob o primeiro prisma, a antecipação é elemento derivado do conteúdo assecuratório da garantia fundamental de acesso à justiça. Sob o segundo, a antecipação é regra instrumental do direito fundamental de prestação jurisdicional efetiva.

\section{A ESTABILIZAÇÃO DA TUTELA JURISDiCIONAL ANTECIPADA EM RAZÃO DA URGÊNCIA E SUA FUNDAMENTALIDADE MATERIAL}

A estabilização da tutela antecipada, a seu turno, é um instituto processual brasileiro cuja inspiração reside no direito processual italiano, com sua tutela sumária, e no direito processual francês, com seu référé. ${ }^{19}$

Humberto Theodoro Jr. (2009. p. 665), ao discorrer sobre a antecipação da tutela, destaca a visão unitária do sistema processual europeu, que unifica as tutelas antecipadas e os procedimentos cautelares.

A tutela sumária italiana pode ocorrer tanto em procedimento autônomo, como no próprio bojo de um processo principal. Pode, também, ser utilizada em hipóteses de urgência ou não. A estabilidade da tutela sumária na Itália varia de acordo com o caso e, não sendo impugnado o provimento, faz coisa julgada sujeita à solução resolutiva. Os efeitos da decisão em procedimento sumário podem vir a ser anulados por sentença de mérito, bem como em razão de renúncia e inatividade do demandante. ${ }^{20}$

O instituto francês do référé, a seu turno, surgiu no âmbito do Châtelet parisiense, por volta de 1685, persistindo até hoje no código processual francês. ${ }^{21}$ De acordo com o código mencionado, o référé é aplicado a todos

${ }^{19}$ Cf. TURRA, Thiago Camatta Chaves. Os reflexos da automatização e estabilização da tutela sumária prevista no projeto de Código de Processo Civil na evolução da tutela de urgência brasileira. In: Celso Hiroshi Iocohama; Adriana Goulart de Sena Orsini (Orgs.). Processo e Jurisdição I: XXIII Encontro Nacional do Conpedi. Florianópolis, SC: CONPEDI, 2014.

${ }^{20}$ GRINOVER, Ada Pellegrini. Tutela jurisdicional diferenciada: a antecipação e sua estabilização. In: Ada Pellegrini Grinover. O processo: estudo e pareceres. $2^{\underline{a}}$ ed. São Paulo, SP: DPJ, 2009, p. 95.

${ }^{21}$ PIGEAU, Eustache-Nicolas. La Procédure civile du Châtelet de Paris et de toutes les jurisdictions ordinaires du royaume: démontrée par principes et mise en action par des formules - Tome Second. Paris: Chez la veuve Desaint, 1787. Disponível em: 
os tipos de jurisdições francesas, correspondendo a um procedimento sumário que pode ser instaurado antes ou no curso do processo e que tem por propósito a regulamentação de uma situação jurídica de modo provisório, gerando um título judicial executável independentemente da interposição de uma ação principal. Apesar de aludir a um caráter de provisoriedade, o Código francês ressalva que a decisão proferida em caráter sumário somente será modificada mediante fatos novos.

Para Desirê Bauermann ${ }^{22}$, a estabilização corresponde à possibilidade de o sistema processual conservar a medida antecipada e sua eficácia independentemente de confirmação por posterior decisão de mérito, conferindo definitividade à solução jurisdicional dada à lide.

Partindo das definições acima destacadas; e uma vez confirmada a premissa de que a antecipação da tutela, em especial a tutela fundamentada na urgência do pedido, é elemento derivado do conteúdo assecuratório da garantia fundamental de acesso à justiça; resta descobrir se assim também pode ser considera a sua estabilização. Ou se, uma vez confirmada a premissa de que a antecipação é regra instrumental do direito fundamental de prestação jurisdicional efetiva, também é esta, ou somente esta, a natureza da estabilização.

A adoção do instituto da estabilização da tutela antecipada pelo ordenamento processual brasileiro já foi defendida em oportunidades como no Projeto de Lei do Senado n.o 186, de 2005, elaborado pelo Instituto Brasileiro de Direito Processual (IBDP) e encaminhado por sua então presidente Ada Pellegrini Grinover. Em sua justificativa, o Projeto, que objetivava modificar os parágrafos quarto e quinto do art. 273 , do atual Código de Processo Civil, para permitir a estabilização da tutela antecipada, afirma-se que tal instituto tem o propósito de tornar definitivo e suficiente o comando antecipatório estabelecido na decisão judicial.

Assim, permitir-se-ia que as próprias partes decidissem sobre a conveniência do prosseguimento da demanda e sua definição pelas vias tradicionais, mediante cognição plena e exauriente, bem como sobre interesse em consequente sentença de mérito.

Hodiernamente, a estabilização encontra-se prevista no Código de Processo Civil de 2015, com hipótese de incidência limitada às tutelas de urgência. De acordo com a nova legislação, haverá estabilização das

$<\underline{\text { http://gallica.bnf.fr/ark:/12148/bpt6k6532520b }}>$. Acesso em: 09 de janeiro de 2017, p. 23.

${ }^{22}$ BAUERMANN, Desirê. Estabilização da tutela antecipada. Revista Eletrônica de Direito Processual - Redp, Ano no 4, VI, 2010, p. 32-48. 
tutelas de urgência se da decisão antecipatória não for interposto recurso, hipótese na qual o processo será extinto. $\mathrm{O}$ mencionado diploma legal estabelece, contudo, que qualquer das partes poderá demandar a revisão, reforma ou invalidação da decisão proferida em cognição sumária mediante ajuizamento de nova ação dentro do prazo prescricional de dois anos contados da ciência de extinção do processo. O Novo Código confere estabilidade à decisão sumária sem que esta constitua coisa julgada, embora só possa ser afastada mediante determinação judicial produzida em ação própria e ajuizada no prazo legal.

Mendonça Sica ${ }^{23}$ conceitua o instituto, conforme previsto pelo Novo CPC, como técnica processual cujo primordial objetivo é tornar facultativa a cognição exauriente submetido à análise jurisdicional, mediante antecipação da tutela e inércia do réu, "sumarizando-se, a um só tempo, a cognição e o procedimento".

Para Scarparo ${ }^{24}$, a previsão de estabilização trazida pelo Código processual de 2015 avaliza a tímida superação, no plano processual, de perspectivas epistemológicas e políticas do pensamento jurídico tradicional, a exemplo da crença de verdade absoluta alcançável por meio da racionalidade e da rejeição à intervenção estatal sobre as liberdades individuais.

A estabilidade da decisão proferida em cognição sumária, contudo, enfrenta fortes críticas por mitigar o princípio constitucional do contraditório. De acordo com Leonardo $\mathrm{Greco}^{25}$, a garantia constitucional da tutela jurisdicional efetiva impõe a ampla participação das partes, com plenas possibilidades de demonstração de seus direitos subjetivos. Para $G_{r e c o}^{26}$, a estabilização da decisão proferida em cognição sumária, mesmo que passível de impugnação em sede recursal, fere não apenas o princípio do contraditório como o do duplo grau de jurisdição.

${ }^{23}$ SICA, Heitor Vitor Mendonça. Doze Problemas e Onze Soluções Quanto à Chamada "Estabilização da Tutela Antecipada". Revista do Ministério Público do Rio de Janeiro, nำ 55, 2015.

${ }^{24}$ SCARPARO, Eduardo. Estabilização da Tutela Antecipada no Código de Processo Civil de 2015. In: Eduardo Fonseca da Costa; Mateus Costa Pereira; Roberto P. Campos Gouveia Filho. Coleção Grandes Temas do Novo CPC. Vol. 6: Tutela Provisória. Salvador, BA: Juspodivm, 2016.

${ }^{25}$ GRECO, Leonardo. Cognição Sumária e coisa julgada. Revista Eletrônica de Direito Processual, Vol. 10, 10, 2012, 275-301.

${ }^{26}$ Cf. GRECO, Leonardo. Cognição Sumária e coisa julgada. Revista Eletrônica de Direito Processual, Vol. 10, 10, 2012.

2 JOURNAL OF INSTITUTIONAL STUDIES 2 (2016) 
No mesmo sentido crítico, Leonardo Faria Schenk ${ }^{27}$, em sua tese de doutorado defendida junto à Universidade Federal do Rio de Janeiro, propõe quatro pressupostos para a sumarização da cognição, quais sejam: (i) a preservação do núcleo essencial do contraditório, relacionado à audiência bilateral; (ii) a predeterminação legislativa, em atenção ao devido processo legal; (iii) a oportunidade de acesso futuro à cognição plena, uma vez que a tutela que resulta de uma cognição sumária não pode ser exaustiva em si; e (iv) o equilíbrio na estabilização, ligado, justamente, à ausência de coisa julgada quando a decisão não derivar de um procedimento capaz de assegurar a cognição plena.

Para Mitidiero ${ }^{28}$, a limitação do direito ao contraditório e do direito à prova inerente à sumarização atua em sentido oposto à busca de uma decisão justa, finalidade do processo civil no Estado Constitucional, de modo que a inafastabilidade da decisão proferida mediante cognição exauriente, mesmo prevendo-se prazo para que o réu provoque a atuação jurisdicional, conforme estabelece o Novo Código ${ }^{29}$, configura afronta ao princípio do processo justo pelo legislador infraconstitucional.

A partir de tais considerações, questiona-se se a estabilização, conforme positivada no ordenamento jurídico brasileiro, está de acordo com sua função e natureza e se coaduna com os princípios constitucionais do processo.

Enquanto instrumento que tem por principal escopo conferir maior segurança jurídica ao beneficiário da antecipação da tutela fundamentada na urgência do pedido, afere-se que o instituto da estabilização guarda, em sua natureza, fundamentalidade material consequente da regra instrumental e do conteúdo assecuratório percebido na antecipação de tutela e advindo do direito e da garantia fundamental de acesso à justiça.

Para confirmar tal aferição, contudo, faz-se necessário investigar se o instituto da estabilização não confronta, em sua própria gênese de tutela

${ }^{27}$ SCHENK, Leonardo Faria. Legitimidade constitucional da cognição sumária: limites impostos pelo contraditório participativo. Tese (Doutorado) - Curso de Programa de Pós-graduação em Direito, Universidade do Estado do Rio de Janeiro, Rio de Janeiro, 2012, p. 170/189/193/230.

${ }^{28}$ MITIDIERO, Daniel. Autonomização e Estabilização da Antecipação da Tutela no Novo Código de Processo Civil. Revista Eletrônica do Tribunal Regional do Trabalho da 9 Região, Vol. 4, 39, 2015.

${ }^{29} \mathrm{O}$ artigo 304, parágrafos quinto e sexto, do Novo CPC, estabelece que decisão que concede a tutela não fará coisa julgada, mas a estabilidade dos respectivos efeitos só será afastada por decisão que a revir, reformar ou invalidar, proferida em ação ajuizada por uma das partes no prazo de 2 (dois) anos. 
proferida mediante cognição inferior, o direito fundamental ao contraditório.

\section{A Estabilização da Tutela Antecipada e o Princípio DO CONTRADITÓRIO NO ÂMBITO DA COGNIÇÃo SUMÁRIA}

A partir do momento que se estabeleceu, no pensamento jurídico, em escala global, a consciência dos assentos políticos-constitucionais de toda a técnica processual de modo concomitante com os aspectos e elementos postos no direito infraconstitucional, superando o apelo dogmático ao que a lei dispõe sobre o processo, desenvolveu-se o que se denomina modelo constitucional do processo, no âmbito nacional.

\section{O Modelo Constitucional do Processo Civil Brasileiro}

A concepção de devido processo constitucional, ou modelo constitucional de processo, surge como sinônimo de processo justo intrinsicamente ligado à concretização dos demais princípios constitucionais do processo, absorvendo-os.

De acordo com Baracho ${ }^{30}$, o modelo constitucional do processo civil tendo por fundamento o exercício da função jurisdicional conforme as normas e os princípios constitucionais, propiciando-se conceitos como "jurisdicionalidade originária" e "jurisdicionalidade constitucionalmente derivada do processo". Para Fix-Zamudio ${ }^{31}$, o direito processual constitucional tem por objeto essencial a análise das garantias constitucionais enquanto instrumentos predominantemente processuais que tem por objetivo o restabelecimento da ordem constitucional quando esta for ignorada ou violada. ${ }^{32}$

Nesse sentido, Bedaque condiciona a técnica processual ao seu fim, o processo justo:

A técnica constitui fator essencial à idéia de processo. Concebido este como

${ }^{30}$ BARACHO, José Alfredo de Oliveira. Teoria Geral do Processo Constitucional.

Revista Brasileira de Estudos Políticos, No. 90, 2004.

${ }^{31}$ FIX-ZAMUDIO, Héctor. Introducción al Derecho Procesal Constitucional. Santiago de Querétaro, QUE: Fundación Universitaria de Derecho, Administración y Política, 2002, p. 31-32.

2 JOURNAL OF INSTITUTIONAL STUDIES 2 (2016) 
instrumento de que a função jurisdicional do Estado se serve para colocar fim às crises existentes no plano do direito material, necessário regular a maneira como ele opera. É fundamental que o instrumento atue segundo técnica adequada e apta a possibilitar que os fins sejam atingidos. Esta é a função das formas e das formalidades processuais, cuja razão de ser encontra explicação fundamentalmente em fatores externos ao próprio processo. Mas processo não é, e nem poderia ser, somente forma. Toda a organização e a estrutura desse mecanismo encontram sua razão de ser nos valores e princípios constitucionais por ele incorporados. A técnica processual, em última análise, destina-se a assegurar o justo processo, ou seja, aquele desejado pelo legislador ao estabelecer o modelo constitucional ou devido processo constitucional. De nada adianta o processo regular do ponto de vista formal, mas substancialmente em desacordo com os valores constitucionais que o regem. ${ }^{33}$

De acordo com Theodoro Jr., o processo constitucionalizado é inerente ao Estado Democrático de Direito e derivado da supremacia da Constituição, consagrando os poderes de acesso à justiça e os deveres de prestação jurisdicional efetiva:

O processo, no Estado Democrático de Direito, está, no campo de seus fundamentos e de sua macro-estrutura, totalmente constitucionalizado. Os poderes de acesso à justiça e os deveres de tutela jurisdicional integram as garantias fundamentais proclamadas pelas constituições dos países onde reina a democracia de forma mais ampla e autêntica. (...) Em virtude do princípio da supremacia da Constituição, o comportamento dos órgãos jurisdicionais durante o desenvolvimento dos processos e o julgamento das causas há, sem dúvida, de ter como ponto de partida a observância das garantias constitucionais do moderno "processo justo". 34

Para Dinamarco 35 , a definição de modelo constitucional do processo civil brasileiro deve considerar as duas grandes vertentes das disposições constitucionais acerca da matéria, quais sejam, i) a tutela constitucional do processo, consistente nos princípios e garantias constitucionais que institucionalizam critérios e parâmetros democráticos a serem

33 BEDAQUE, José Roberto dos Santos. Efetividade do processo e técnica processual. $3^{\text {a }}$ ed. São Paulo, SP: Malheiros Editores, 2010, p. 26.

34 THEODORO JR., Humberto. Direito Processual Constitucional. Revista Estação

Científica (Ed. Especial Direito), Vol. 1, 4, 2009, p. 39-40.

${ }^{35}$ Cf. DINAMARCO, Cândido Rangel. A instrumentalidade do processo. $15^{\mathfrak{a}}$ ed. São

Paulo, SP: Malheiros, 2013. 
observados pela atividade legislativa e pela atividade jurisdicional; ii) e a jurisdição constitucional das liberdades, integrada por específicos modos de tutela jurisdicional diferenciada assentados em plano constitucional e disponibilizados como instrumentos de complementação à garantia genérica de acesso à justiça. ${ }^{36}$

No plano infraconstitucional, destinado à disciplina da técnica processual, as Reformas do Código Processual brasileiro operadas entre 1996 e 2006, de acordo com Dinamarco ${ }^{37}$, contribuíram em quatro grandes vertentes que possibilitam uma definição de modelo processual. Dentre as vertentes destacadas pelo autor, importa ao presente trabalho as medidas de aceleração da tutela jurisdicional, consistentes, por exemplo, na técnica antecipatória da tutela e na técnica monitória ${ }^{38}$.

Nessa linha, tomando-se o modelo constitucional de processo civil brasileiro enquanto manifestação concomitante de aspectos constitucionais e da técnica processual infraconstitucionalmente estabelecida, percebe-se o instituto da estabilização da tutela antecipada de urgência como pertencente ao plano constitucional, no que tange à tutela constitucional do processo, em especial em relação à garantia de tutela jurisdicional efetiva; bem como pertencente ao plano infraconstitucional, por meio das técnicas de aceleração da tutela jurisdicional.

$\mathrm{O}$ instituto deve, ainda, ser interpretado em consonância com os demais princípios e garantias constitucionais do processo, que, de acordo com a primeira vertente do modelo constitucional destacada por Dinamarco, cumpre papel de orientação da atividade jurisdicional. ${ }^{39}$

Nesse ponto do trabalho, a discussão acerca do instituto objeto de estudo será especificamente direcionada por uma das garantias constitucionais do processo: o contraditório.

${ }^{36}$ DINAMARCO, Cândido Rangel. A instrumentalidade do processo. 15ª ed. São Paulo, SP: Malheiros, 2013, p. 182-183.

${ }_{37}$ DINAMARCO, Cândido Rangel. A instrumentalidade do processo. 15ª ed. São Paulo, SP: Malheiros, 2013, p. 183.

${ }^{38}$ Dinamarco destaca, também, i) a oferta de tutelas coletivas; ii) as medidas de universalização da jurisdição direcionada ao cidadão de menor poder aquisitivo e às caudas de menor valor; e iii) as medidas tendentes a assegurar a efetividade do processo mediante o esforço de ampliação do poder do juiz de impor suas decisões, a exemplo das multas pelo não cumprimento de obrigações.

${ }^{39}$ Cf. DINAMARCO, Cândido Rangel. A instrumentalidade do processo. $15^{\mathfrak{a}}$ ed. São Paulo, SP: Malheiros, 2013. 


\section{O Contraditório no Modelo Constitucional do Processo Civil Brasileiro}

A ação, como direito de demandar, prescinde de um direito a uma espécie de réplica, ou direito de defesa. Couture ${ }^{40}$ afirma que se a ação é um instituto civilizatório substitutivo à vingança, a exceção é o substitutivo civilizatório da defesa. Para o autor, o litígio é caracterizado por uma ideia de bilateralidade de modo que as partes se encontrem em pé de igualdade no conflito. Essa igualdade, no âmbito do processo, seria, pois, uma manifestação do princípio da igualdade dos indivíduos perante a lei. ${ }^{41}$

O autor defende, ainda, o processo como um método de debate no qual participam elementos humanos, tais como juízes, partes, testemunhas e peritos. O debate, contudo, por si mesmo não tem sentido, sendo o processo, portanto, uma estrutura dialética e teleológica. De tal sorte, Couture complementa a ideia de processo enquanto debate forense com o princípio do contraditório e com a dimensão de finalidade..$^{42}$

Para Baracho ${ }^{43}$, o direito ao contraditório decorre da exigência de coparticipação paritária dos sujeitos no processo, possibilitando a construção de uma decisão judicial racional e a garantia de um "processo justo". De acordo com o autor, a paridade dos litigantes proporciona a "projeção endoprocessual do princípio constitucional da igualdade formal".

Nery Jr., ao tratar dos princípios constitucionais do processo no direito brasileiro, afirma que o contraditório, além de fundamentalmente ser constituído como manifestação do Estado de Direito, tem íntima ligação com a igualdade das partes, visto que o texto constitucional quer significar tanto direito de ação quanto direito de defesa enquanto manifestações do contraditório. Destaca-se, ainda, o binômio ciência-

${ }^{40}$ Cf. COUTURE, Eduardo J. Introdução ao Estudo do Processo Civil: discursos, ensaios e conferências. Trad. Hiltomar Martins de Oliveira. Belo Horizonte, MG: Editora Líder, 2003.

${ }^{41}$ COUTURE, Eduardo J. Introdução ao Estudo do Processo Civil: discursos, ensaios e conferências. Trad. Hiltomar Martins de Oliveira. Belo Horizonte, MG: Editora Líder, 2003, p. 29.

${ }^{42}$ COUTURE, Eduardo J. Introdução ao Estudo do Processo Civil: discursos, ensaios e conferências. Trad. Hiltomar Martins de Oliveira. Belo Horizonte, MG: Editora Líder, 2003, p. 44.

43 BARACHO, José Alfredo de Oliveira. Teoria Geral do Processo Constitucional. Revista Brasileira de Estudos Políticos, No. 90, 2004. 
participação inerente ao contraditório. Para o autor, a garantia constitucional em comento é compreendida pela necessidade de conhecimento da existência de ação e de todos os atos processuais e pela possibilidade de manifestação das partes sobre todos esses atos. ${ }^{44}$

Segundo Dinamarco ${ }^{45}$, a garantia do contraditório é imprescindível a qualquer processo, seja jurisdicional ou não, por expressa imposição do texto constitucional, conforme art. $5^{\circ}$, inciso LV. Para o processualista, o contraditório detém dupla destinação, significando, em primeiro lugar, que a lei deve instituir meios de participação das partes no processo e que o juiz deve franquear-lhes tais meios. Em segundo plano, significa que o próprio juízo deve participar da relação processual preparando o julgamento. Em síntese, a garantia do contraditório corresponderia a um direito das partes e a uma série de deveres do juiz. ${ }^{46}$

\subsection{O Contraditório Prévio}

O contraditório prévio é caracterizado pela possibilidade de participação das partes em momento anterior à formulação de decisão pelo julgador, possibilitando a efetiva capacidade de influência do autor e do réu na formação do convencimento do magistrado. A modalidade prévia de contraditório é, portanto, a regra no modelo constitucional do processo civil brasileiro. ${ }^{47}$

Para $\mathrm{Greco}^{48}$, na medida em que a decisão judicial goza de força executiva, capaz de invadir, de pronto, a esfera jurídica dos destinatários, o modelo processual idôneo predeterminado pelo legislador pressupõe o contraditório prévio, que oportunize às partes o pleno exercício de suas faculdades defensivas. ${ }^{49}$

${ }^{44}$ NERY JÚNIOR, Nelson. Princípios do processo civil na Constituição Federal. $7^{\mathrm{a}}$ ed. São Paulo, SP: Editora Revista dos Tribunais, 2002, p. 134-139.

${ }^{45}$ Cf. DINAMARCO, Cândido Rangel. A instrumentalidade do processo. 15a ed. São

Paulo, SP: Malheiros, 2013.

${ }^{46}$ DINAMARCO, Cândido Rangel. A instrumentalidade do processo. 15ª ed. São

Paulo, SP: Malheiros, 2013, p. 220-224.

${ }^{47}$ PAIM, Gustavo Bohrer. Estabilização da tutela antecipada. Porto Alegre, RS:

Livraria do Advogado Editora, 2012, p. 116.

${ }^{48}$ Cf. GRECO, Leonardo. Cognição Sumária e coisa julgada. Revista Eletrônica de

Direito Processual, Vol. 10, 10, 2012.

${ }^{49}$ GRECO, Leonardo. Cognição Sumária e coisa julgada. Revista Eletrônica de Direito

Processual, Vol. 10, 10, 2012, p. 275-301.

2 JOURNAL OF INSTITUTIONAL STUDIES 2 (2016) 
Schenk ${ }^{50}$ defende que a garantia ao contraditório impõe ao legislador ordinário o limite de atuação no que tange à sumarização da cognição processual. Para o autor, não foi dado ao legislador a competência de banir o contraditório em qualquer dos processos ou procedimentos judiciais, devendo sempre existir o contraditório prévio ainda que em seu núcleo mínimo. A única ressalva aceita pelo processualista consiste na tutela de urgência consubstanciada no risco de perecimento do direito, reconhecendo, aqui, o diferimento do contraditório por imperativo de efetividade da atuação jurisdicional. Nessa perspectiva, Schenk ${ }^{51}$ defende o respeito ao núcleo mínimo de contraditório prévio no procedimento antecedente materializado em audiência bilaterial prévia. ${ }^{52}$

\subsection{O Contraditório Postecipado}

Embora a regra no direito processual seja a observância do contraditório em momento prévio ao convencimento do juízo e à prolação de decisões, existem situações nas quais o direito restringe a ampla participação das partes, tais como nos processos de execução e nos procedimentos sumário e sumaríssimo.

Pontes de Miranda ${ }^{53}$ já admitia hipóteses de retardamento da defesa sem que se admita em qualquer hipótese que o processo civil vede ou omita o contraditório. A postergação ou a inversão do contraditório são técnicas utilizadas para sumarização do procedimento, o que se justifica pelo direito material e sua urgência.

${ }^{50}$ Cf. SCHENK, Leonardo Faria. Legitimidade constitucional da cognição sumária: limites impostos pelo contraditório participativo. Tese (Doutorado) - Curso de Programa de Pós-graduação em Direito, Universidade do Estado do Rio de Janeiro, Rio de Janeiro, 2012.

${ }^{51}$ SCHENK, Leonardo Faria. Legitimidade constitucional da cognição sumária: limites impostos pelo contraditório participativo. Tese (Doutorado) - Curso de Programa de Pós-graduação em Direito, Universidade do Estado do Rio de Janeiro, Rio de Janeiro, 2012, p. 170/189/193/230.

${ }^{52} \mathrm{O}$ termo "audiência bilateral prévia" é aqui utilizado como sinônimo de contraditório enquanto direito que as partes detêm de conhecer e se manifestar no processo.

53 PONTES DE MIRANDA, Francisco Cavalcanti. Comentários à Constituição de 1967: com a Emenda n.1 de 1969 - Tomo V. 2ª ed. São Paulo, SP: Revista dos Tribunais, 1971, p. 235-236. 
Nesse sentido, Del Debbio ${ }^{54}$ trata de dois tipos de contraditório postecipado, um de natureza diferida, cujo exercício se dá após a apreciação da tutela inicial, e outro de natureza eventual, que somente é exercido caso o réu inicie processo apartado. De tal modo, a inversão do contraditório visa proteger situações nas quais o legislador julga conveniente o sacrifício da ideia de certeza e segurança advinda da cognição exauriente, operando em razão da efetividade e de graus de probabilidade do direito.

Olvídio Baptista, ao trabalhar com o conceito de contraditório eventual, o qualifica em duas modalidades distintas, a primeira ocorre com a tutela inicial do interesse do autor, transferindo-se ao demandado o ônus de provocar o contraditório em demanda incidental. Na segunda modalidade, o ônus de provocar o contraditório continua transferido ao demandado que o exercerá, dessa vez, em ação autônoma subsequente. ${ }^{55}$

Nesse sentido, seguindo as inspirações francesa, italiana e monitória, o procedimento antecedente que acarrete na estabilização da tutela antecipada de urgência possibilita a supressão do contraditório prévio e submete o demandado ao exercício do contraditório eventual, seja em sede recursal seja em ação autônoma posterior.

\section{Contraditório e Procedimento Sumário na Estabilização da Tutela Antecipada de Urgência}

A estabilização da tutela antecipada de urgência, conforme observado, tem o propósito de empregar maior grau de segurança jurídica ao jurisdicionado cujo provável direito fora assegurado por decisão proferida em sede de procedimento sumário. Além disso, o instituto é adotado pelo Novo Código de Processo Civil com a promessa de diminuir o grau de litigiosidade no Judiciário brasileiro, pacificando conflitos por meio de procedimentos especiais pautados na celeridade.

A novidade trazida pelo instituto ao Processo brasileiro reside, pois, na possibilidade de estabilização com força de definitividade de uma decisão de natureza sumária que, por definição, fora proferida sem a cognição plena dos fatos.

Uma das características definidoras dos procedimentos sumários

${ }^{54}$ Cf. DEL DEBBIO, Cristiano Rodrigo. Tutela jurisdicional diferenciada: técnicas de sumarização da cognição. Dissertação (Mestrado) - Faculdade de Direito, Universidade de São Paulo, São Paulo, 2005.

55 SILVA, Ovídio Araujo Baptista da. O contraditório nas ações sumárias: da sentença liminar à nulidade da sentença. Rio de Janeiro, RJ: Forense, 2003, p. 268-269. 
reside na limitação ao contraditório por decorrência lógica da restrição do campo cognitivo. Isto porque o contraditório, em sua forma clássica, sempre pleno e prévio, impossibilita a concretização de outras garantias constitucionais do processo, a exemplo da própria efetividade da tutela jurisdicional no caso concreto.

Para Marinoni, a preocupação mais recente do processo corresponde à própria prestação efetiva de uma proteção jurisdicional, de uma resposta da Jurisdição:

A demonstração de que a tutela do direito pode ocorrer com base em cognição sumária deixa evidenciado o equívoco daqueles que pensam que a "satisfatividade" fundada em cognição sumária não é propriamente "satisfativa fática" (ou algo que não tem relevância jurídica). Quem relaciona desta forma confunde satisfação do direito material (que obviamente pode ocorrer mediante decisão fundada em cognição sumária) e satisfação processual (coisa julgada material). Mais do que isto: aquele que não dá importância à "satisfação fática", mostra não estar atento à preocupação mais recente da doutrina, vale dizer, à preocupação com a "tutela dos direitos", uma vez que, na perspectiva do consumidor do serviço jurisdicional, o que vale é a "tutela do direito", pouco importando que esta venha por meio de decisão de cognição sumária ou mediante uma decisão de cognição exauriente e definitiva. ${ }^{56}$

A sumariedade para Bedaque ${ }^{57}$, assim como no conceito de Chiovenda ${ }^{58}$ já mencionado neste trabalho, pode decorrer de uma restrição da cognição tanto no plano vertical, caracterizada pelo autor como cognição superficial, uma vez que o juiz analisa todos os fatos constitutivos da demanda e da defesa de forma não exauriente; quanto no plano horizontal, caracterizada como cognição parcial, tendo por objeto apenas parte dos fatos relevantes para a demanda.

Zavascki ${ }^{59}$ também reconhece a superficialidade, no plano vertical, da cognição sumária em relação à cognição exauriente. O autor também

${ }^{56}$ MARINONI, Luiz Guilherme. Antecipação de tutela. 12ª ed. São Paulo, SP: Revista dos Tribunais, 2011, p. 126.

${ }^{57}$ BEDAQUE, José Roberto dos Santos. Efetividade do processo e técnica processual. $3^{a}$ ed. São Paulo, SP: Malheiros Editores, 2010, p. 240.

${ }^{58}$ Cf. CHIOVENDA, Giuseppe. Instituições de Direito Processual Civil. Trad. José Guimarães Menegale. São Paulo, SP: Saraiva, 1965.

${ }^{59}$ Cf. ZAVASCKI, Teori Albino. Antecipação da Tutela. $7^{a}$ ed. São Paulo, SP: Saraiva, 2009.

2 JOURNAL OF INSTITUTIONAL STUDIES 2 (2016) 
aborda o conceito horizontal da sumariedade como cognição menos aprofundada típica de procedimentos especiais, tais como nas ações possessórias. ${ }^{60}$

No mesmo sentido, segue Marinoni ${ }^{11}$, que trata da cognição sumária no plano vertical como juízo de verossimilhança que, no âmbito das tutelas provisórias, objetiva, na hipótese da antecipação da tutela de urgência, realizar antecipadamente um direito em vista de uma situação de perigo (2011, p. 34).

Nessa perspectiva, o juiz que concede a tutela sumária não declara ou constitui direito, mas afirma a sua probabilidade e, havendo situação de urgência, privilegia a efetividade da prestação jurisdicional, diferindo o exercício do contraditório.

\section{CONSIDERAÇÕES FINAIS}

O instituto da estabilização da tutela antecipada de urgência, inspirado no processo civil francês e italiano e positivado no Código de Processo Civil de 2015, tem como principal escopo conferir maior segurança jurídica ao beneficiário de uma tutela jurisdicional diferenciada fundada na urgência da situação fática que a justifica. Nessa perspectiva, objetiva instrumentalizar de forma ampla o acesso à justiça em seu sentido material.

$\mathrm{O}$ instituto guarda natureza de fundamentalidade material em seu conteúdo na medida em que confere maior grau de estabilidade à tutela jurisdicional que instrumentaliza o direito fundamental de acesso à justiça e que corresponde a um conteúdo assecuratório derivado da garantia fundamental de acesso à justiça.

Nessa linha de construção argumentativa, defende-se e demonstra-se o grau instrumental e assecuratório de direito e de garantia fundamental reservado à própria estabilização da tutela, e não somente à tutela diferencia em si.

A tutela diferenciada objeto da estabilização, contudo, é preferida no âmbito de uma cognição sumária que, por definição, restringe a atuação do outro no processo, mitigando o direito fundamental ao contraditório. Havendo, em sua gênese, uma violação necessária ao contraditório,

${ }^{60}$ ZAVASCKI, Teori Albino. Antecipação da Tutela. $7^{\mathfrak{a}}$ ed. São Paulo, SP: Saraiva, 2009, p. 43.

${ }^{61}$ MARINONI, Luiz Guilherme. Antecipação de tutela. 12ª ed. São Paulo, SP: Revista dos Tribunais, 2011, p. 34. 
insustentável se torna a defesa de uma materialidade material do instituto da estabilização da tutela antecipada de urgência.

Essa tese, contudo, é afastada pela concepção de contraditório que, em casos de urgência, se coloca em coexistência com a própria efetividade da prestação jurisdicional. Dessa forma, a adoção das concepções de contraditório postecipado, seja em modalidade diferida, seja em modalidade eventual, não significa a negação ao contraditório, mas a negação de sua aplicação absoluta em sacrifício da efetividade da prestação jurisdicional.

De tal sorte, verifica-se na análise do instituto da estabilização da tutela antecipada, tomando-se como limite objetivo o direito fundamental ao contrário, um reforço de sua natureza materialmente fundamental, na medida em que se reafirma seu escopo de concretizar a efetividade da prestação jurisdicional.

\section{REFERÊNCIAS}

ALEXY, Robert. Teoria dos Direitos Fundamentais. Trad. Virgílio Afonso da Silva. São Paulo, SP: Malheiros, 2008.

BARACHO, José Alfredo de Oliveira. Teoria Geral do Processo

Constitucional. Revista Brasileira de Estudos Políticos, No. 90, 2004.

CHIOVENDA, Giuseppe. Instituições de Direito Processual Civil.

Trad. José Guimarães Menegale. São Paulo, SP: Saraiva, 1965.

COUTURE, Eduardo J. Introdução ao Estudo do Processo Civil:

discursos, ensaios e conferências. Trad. Hiltomar Martins de Oliveira. Belo Horizonte, MG: Editora Líder, 2003.

DINAMARCO, Cândido Rangel. A instrumentalidade do processo. $15^{\mathrm{a}}$ ed. São Paulo, SP: Malheiros, 2013. 
BAUERMANN, Desirê. Estabilização da tutela antecipada. Revista Eletrônica de Direito Processual - Redp, Ano no 4, VI, 2010.

BEDAQUE, José Roberto dos Santos. Efetividade do processo e técnica processual. 3aa ed. São Paulo, SP: Malheiros Editores, 2010.

DEL DEBBIO, Cristiano Rodrigo. Tutela jurisdicional diferenciada: técnicas de sumarização da cognição. Dissertação (Mestrado) Faculdade de Direito, Universidade de São Paulo, São Paulo, 2005.

FIX-ZAMUDIO, Héctor. Introducción al Derecho Procesal

Constitucional. Santiago de Querétaro, QUE: Fundación Universitaria de Derecho, Administración y Política, 2002

GOLDSCHMIDT, James. Derecho Procesal Civil. Trad. Leonardo Pietro Castro. Barcelona: Editorial Labor, S.A., 1936.

GRECO, Leonardo. Cognição Sumária e coisa julgada. Revista Eletrônica de Direito Processual, Vol. 10, 10, 2012.

GRINOVER, Ada Pellegrini. Tutela jurisdicional diferenciada: a antecipação e sua estabilização. In: Ada Pellegrini Grinover. O processo: estudo e pareceres. $2^{\underline{a}}$ ed. São Paulo, SP: DPJ, 2009.

GUERRA, Marcelo Lima. Estudos sobre o processo cautelar. São Paulo, SP: Malheiros, 1994.

GUERRA FILHO, Willis Santiago. Processo Constitucional e Direitos Fundamentais. 6 $6^{\mathrm{a}}$ ed. São Paulo, SP: SRS Editora, 2009.

LEONEL, Ricardo de Barros. Tutela jurisdicional diferenciada. São Paulo, SP: Revista dos Tribunais, 2010.

MARINONI, Luiz Guilherme. Antecipação de tutela. 12ª ed. São Paulo, 
SP: Revista dos Tribunais, 2011.

MITIDIERO, Daniel. Autonomização e Estabilização da Antecipação da Tutela no Novo Código de Processo Civil. Revista Eletrônica do Tribunal Regional do Trabalho da 9a Região, Vol. 4, 39, 2015.

NERY JÚNIOR, Nelson. Princípios do processo civil na Constituição Federal. $7^{\mathrm{a}}$ ed. São Paulo, SP: Editora Revista dos Tribunais, 2002.

OLIVEIRA, Carlos Alberto Alvaro de. O processo civil na perspectiva dos direitos fundamentais. Cadernos do Programa de Pós-Graduação em Direito - UFRGS, Vol. 2, 4, 2004. Disponível em:

$<$ http://www.seer.ufrgs.br/index.php/ppgdir/article/view/49187/30822>. Acesso em: 09 de setembro de 2015.

PAIM, Gustavo Bohrer. Estabilização da tutela antecipada. Porto Alegre, RS: Livraria do Advogado Editora, 2012.

PEREIRA, Alex Costa. Tutela sumária: a estabilização da tutela antecipada e sua adequação ao modelo constitucional do processo civil brasileiro. Tese (Doutorado em Direito Processual) - Faculdade de Direito, Universidade de São Paulo, São Paulo, 2012. Disponível em: $<$ http://www.teses.usp.br/teses/disponiveis/2/2137/tde-26032013103821/>. Acesso em: 26 de abril de 2015.

PIGEAU, Eustache-Nicolas. La Procédure civile du Châtelet de Paris et de toutes les jurisdictions ordinaires du royaume: démontrée par principes et mise en action par des formules - Tome Second. Paris: Chez la veuve Desaint, 1787. Disponível em: $<$ http://gallica.bnf.fr/ark:/12148/bpt6k6532520b $>$. Acesso em: 09 de janeiro de 2017.

PONTES DE MIRANDA, Francisco Cavalcanti. Comentários à Constituição de 1967: com a Emenda n.1 de 1969 - Tomo V. $2^{\underline{a}}$ ed. São 
Paulo, SP: Revista dos Tribunais, 1971.

PONTES DE MIRANDA, Francisco Cavalcanti. Tratado das ações:

Ação, Classificação e Eficácia, Tomo I. $2^{a}$ ed. Rio de Janeiro, RJ: Editora Revista dos Tribunais, 1972.

PROTO PISANI, Andrea. L'istruzioni nei procedimenti sommari. Il Foro Italiano, Vol. 125, 2, 2002.

ROCHA, José de Albuquerque. Teoria Geral do Processo. 9a ed. São Paulo, SP: Editora Atlas, 2007.

SCARPARO, Eduardo. Estabilização da Tutela Antecipada no Código de Processo Civil de 2015. In: Eduardo Fonseca da Costa; Mateus Costa Pereira; Roberto P. Campos Gouveia Filho. Coleção Grandes Temas do Novo CPC. Vol. 6: Tutela Provisória. Salvador, BA: Juspodivm, 2016.

SENADO FEDERAL. Projeto de Lei no $\mathbf{1 8 6}$, de 25 de maio de 2005. Projeto de Lei do Senado № 186, de 2005. Brasília.

SCHENK, Leonardo Faria. Legitimidade constitucional da cognição sumária: limites impostos pelo contraditório participativo. Tese (Doutorado) - Curso de Programa de Pós-graduação em Direito, Universidade do Estado do Rio de Janeiro, Rio de Janeiro, 2012.

SICA, Heitor Vitor Mendonça. Doze Problemas e Onze Soluções Quanto à Chamada "Estabilização da Tutela Antecipada". Revista do Ministério Público do Rio de Janeiro, no 55, 2015.

SILVA, Ovídio Araujo Baptista da. O contraditório nas ações sumárias: da sentença liminar à nulidade da sentença. Rio de Janeiro, RJ: Forense, 2003.

THEODORO JR., Humberto. Curso de Direito Processual Civil: 
processo de execução e cumprimento da sentença, processo cautelar e tutela de urgência - Volume II. 44 ${ }^{\mathrm{a}}$ ed. Rio de Janeiro, RJ: Forense, 2009.

. Direito Processual Constitucional. Revista Estação Científica (Ed. Especial Direito), Vol. 1, 4, 2009.

TURRA, Thiago Camatta Chaves. Os reflexos da automatização e estabilização da tutela sumária prevista no projeto de Código de Processo Civil na evolução da tutela de urgência brasileira. In: Celso Hiroshi Iocohama; Adriana Goulart de Sena Orsini (Orgs.). Processo e Jurisdição I: XXIII Encontro Nacional do Conpedi. Florianópolis, SC: CONPEDI, 2014.

ZAVASCKI, Teori Albino. Antecipação da Tutela. $7^{a}$ ed. São Paulo, SP: Saraiva, 2009.

A Estabilização da Tutela Antecipada como Instrumento de Efetividade da Jurisdição em face do Direito Fundamental ao Contraditório The Stabilization of the Summary Judgment of Urgency as an Instrument of Effectiveness of Jurisdiction Regarding the audi alteram partem Principle

Submetido em: 2016-10-17

Aceito em: 2017-01-30 